\title{
Strama - A SWEDISH WORKING MOdEL FOR CONTAINMENT OF ANTIBIOTIC RESISTANCE
}

\author{
S Mölstad ${ }^{1,2}$, 0 Cars $^{3}$, Johan Struwe (johan.struwe@smi.ki.se) ${ }^{3}$ \\ 1. Unit of Research and Development in Primary Care, Jönköping, Sweden \\ 2. Department of Medical and Health Sciences, Linköping University, Linköping, Sweden \\ 3. The Swedish Strategic Programme against Antibiotic Resistance - Strama, Solna, Sweden
}

\begin{abstract}
The overall aim of Strama (The Swedish Strategic Programme Against Antibiotic Resistance) is to preserve the effectiveness of antibiotics in humans and animals. Strama is organised at two levels: a network of independent local multidisciplinary groups in each county that provide prescribers with feedback on antibiotic use and resistance and implement guidelines; and a national executive working group funded by the government. To gain an insight into antibiotic use, Strama has conducted several large diagnosisprescribing surveys in primary care, in the hospital settings and in nursing homes. National antibiotic susceptibility data for Sweden and mandatory notification show that in recent years the proportion of Streptococcus pneumoniae with decreased sensitivity to penicillin $\mathrm{V}$ has stabilised (around $6 \%$ ), but the number of notified cases of meticillin-resistant Staphylococcus aureus (MRSA) has increased and ESBL-producing Enterobacteraceae have turned into an endemic situation. Still, Sweden is among the countries with the lowest rates of MRSA ( $<1 \%), S$. pneumoniae can still be treated with penicillin $\mathrm{V}$ and the rate of Escherichia coli-producing ESBLs is below $5 \%$. Strama's activities have contributed to a steady decrease in antibiotic use from the mid 1990s until 2004 (when total use slowly started to increase again) without measurable negative consequences. Regular collaboration with national and regional news media has been one of the key strategies.
\end{abstract}

\section{Background}

Increasing use of antibiotics and spread of penicillin-resistant pneumococcal clones in the beginning of the 1990s alarmed the medical profession and authorities in Sweden. Strama (The Swedish Strategic Programme against Antibiotic Resistance) started as an informal network between experts and authorities in 1994. In 2000, Strama, in close cooperation with the National Board of Health and Welfare, prepared a proposal for a national action plan to contain antibiotic resistance [1]. This proposal was later developed into a governmental bill "Strategy to prevent antibiotic resistance and health-care associated infections" [2], which was passed in 2006. Since then Strama has been institutionalised as an independent governmental body with an annual budget of 10 million Swedish crowns from the Ministry of Health and Social Affairs. Recently, a corresponding Strama VL (Veterinary and Food) coordinated by the National Veterinary Institute has been inaugurated.

The overall aim of Strama's activities is to preserve the effectiveness of antibiotics in humans and animals. Strama is organised at two levels: local groups in each county and a national executive working group funded by the government. Detailed overviews of the efforts to contain antibiotic resistance in Sweden and of the systems for the surveillance of antibiotic consumption and antibiotic resistance have been published [3-5].

\section{Local Strama groups}

Strama developed as a network with nodes of independent local groups coordinated by each county department for communicable disease control. The local groups are the drivers of Strama activities. These local groups usually comprise specialists in communicable diseases, infectious diseases, clinical microbiology, infection control, general practice and pharmacy. Paediatricians as well as ear, nose and throat specialists are common additional members. In most counties there is a close link to the local drug and therapeutics committee.

The guiding principle underlying local Strama activities is to promote the rational use of antibiotics by providing prescribers with feedback on local or individual data on prescription for comparison with other prescribers and prevailing therapy recommendations. Local data on antibiotic resistance is provided by the clinical microbiology laboratory. Other important activities are to develop local therapeutic guidelines and to organise courses and lectures for local physicians and other health-care workers at different levels of training. While initially focussing on general practice, parallel groups targeting hospital care were recently developed in an increasing number of counties and regions.

There is no formal reporting on either activities or on budgets from the local groups to the national level. Data from local projects are shared and discussed at national meetings at least once annually. A problem is that many of the local activities rely on personal commitment from devoted physicians and that a formal mandate and financial support from the county council is still missing in many counties. However, the awareness of a need for such targeted and mandated activities to contain antibiotic resistance is slowly increasing and a growing number of Strama groups (or equivalent bodies) are now supported.

\section{Strama at national level}

While the local groups coordinate activities targeting local prescribers, the national executive working group is responsible for national coordination of information and meetings, initiating studies in areas where knowledge gaps have been identified, disseminating Strama's results and acting as a node for international collaboration. The executive working group is supported by a secretariat. 
Strama has a formal regulatory instruction from the Swedish government. The chairman is appointed by the government and reports directly to the Ministry of Health and Social affairs. The Strama governance board has members from the Swedish Institute for Infectious Disease Control, the National Board of Health and Welfare, the National Veterinary Institute, the Medical Products Agency, the Swedish Corporation of Pharmacies (Apoteket AB), the Swedish Association of Local Authorities and Regions, the Swedish Reference Group for Antibiotics and the professional societies for infectious diseases, infection control and communicable diseases. The executive working group has a broad multisectorial composition including several clinicians and meets at least bimonthly to outline working-directions and priorities and to define areas needing further studies.

Although penicillin resistance in S. pneumoniae in the community was the first target of Strama, national activities have continuously expanded and today include many additional fields e.g. hospital care, intensive care ("ICU-Strama") [6-7], nursing homes, daycare centers and clinical trials. ICU-Strama has developed a close collaboration with the Swedish Intensive Care Registry (SIR) and is now integrated as a part of its national quality registry. Experiences from ICU-Strama have been incorporated into the European network care-ICU [8].

Strama has co-organised several workshops yielding national recommendations for the treatment of various diagnoses common in general practice such as acute otitis media, acute pharyngotonsillitis, impetigo, acute sinusitis, urinary tract infections and lower respiratory tract infections.

The national office supports the local groups, coordinates different activities, supplies national data and manages a national website (www.strama.se). A national meeting with annual updates on scientific and medical aspects of antibiotic resistance, statistics on antibiotic use and resistance as well as results and analysis of performed studies, interventions and educational programmes is held for the members of the local Strama groups and other interested parties. Abstracts and/or presentations are distributed via the website for further dissemination as a rule. News, regional and national data on antibiotic use and resistance are regularly updated as well as treatment guidelines and results from Strama-funded projects. A physician is contracted who regularly distributes relevant news in the field from the medical press and other sources and "Strama News" containing summaries of relevant recent scientific publications is distributed by email to listed subscribers about eight times a year.

Occasionally, a more acute situation unfolds and calls for more extensive actions. This was the case when it became evident that Enterobacteriaceae producing extended-spectrum betalactamases (ESBLs) rapidly became increasingly prevalent and caused outbreaks. This prompted Strama to organise a workshop whose findings were then translated into a proposal for a national action plan [9].

\section{Antibiotic utilisation}

Strama has taken the responsibility for the regular analysis of antibiotic consumption at national level. A detailed description and analysis of antibiotic consumption and resistance: "SWEDRES - A report on Swedish antimicrobial utilisation and resistance in human medicine" is published yearly in collaboration with Swedish Institute for Infectious Disease Control (SMI) and is co-produced and packaged with the corresponding veterinary report SVARM [5]. Following the increased awareness and the inception of the Strama programme, the total antibiotic sales in general practice in Sweden continuously decreased in the 1990s until 2004. In contrast, the other Nordic countries have either remained at a comparatively higher level of antibiotic use (Iceland and Finland) or experienced an uninterrupted increasing trend. According to official figures from the respective medicine agencies in the Nordic countries, Sweden has had the lowest antibiotic use since 2003. However, since 2004 a slow rise, mainly attributable to increased prescription of penicillin to children, has been seen again (Figure 1 ).

\section{Drug-prescribing surveys and other studies}

To learn more about compliance with guidelines in general practice and about antibiotic use in the hospital setting, Strama has initiated and coordinated several large diagnosis- prescribing surveys. The use of antibiotics in primary care and compliance with the recommendations from the workshops and the quality indicators defined by the General Practitioners Association (SFAM) have been studied in diagnosis-prescribing surveys conducted in 2000, 2002 and 2005 [10-15]. These studies comprised altogether 15,371 patients with infectious symptoms treated by around 600 general practitioners (GPs). The studies showed high antibiotic prescribing in acute otitis media, acute pharyngotonsillitis and acute bronchitis, indicating that the current treatment guidelines for these conditions had not been not fully implemented. For the treatment of uncomplicated urinary tract infections a shift from the use of trimethoprim and fluoroquinolones to pivmecillinam and nitrofurantoin is recommended. A restricted use of fluoroquinolones was advocated already in 1996, [16] leading to a decreasing trend as clearly documented in the surveys.

\section{F I G U R E}

Antibiotic use in outpatients, methenamine excluded, in defined daily doses (DDD) per 1,000 inhabitants and per day, Sweden, 1978-2007

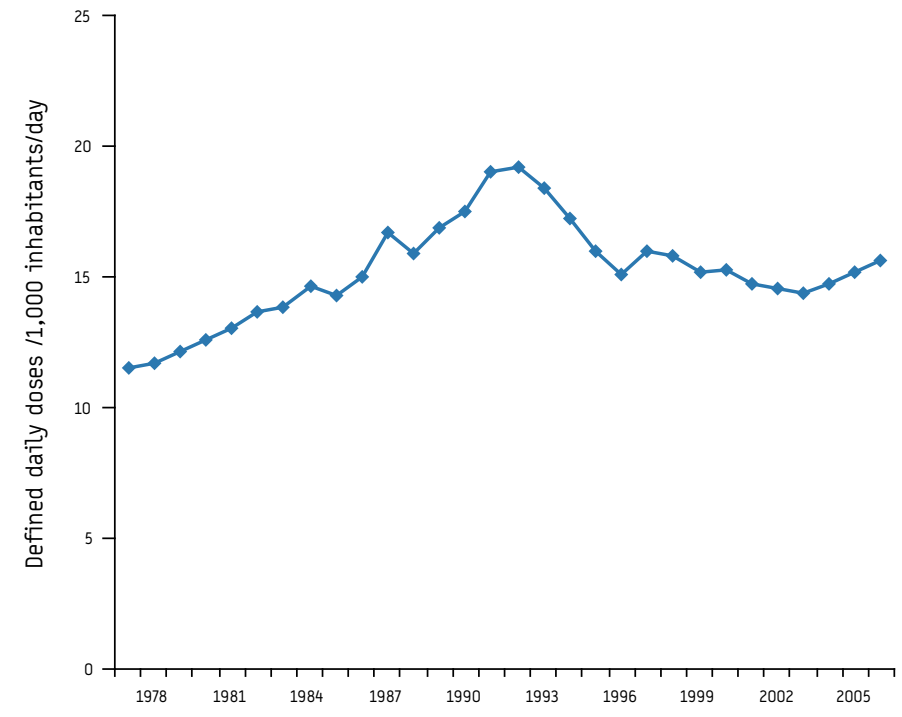

Source: Apoteket AB 
To address antibiotic use in the hospital setting Strama initiated and coordinated nationwide point prevalence studies in 2003 , 2004 and 2006. The number of participating hospitals was 54, 49 and 64 and the number of covered hospitalised patients (proportion of all hospitalised patients in somatic clinics in the respective years) was 13,536 (60\%), 11,348 (50\%) and 17,113 (80\%), respectively [17]. Data in these studies were reported by a webbased system and results were likewise available for the participating Strama groups. The studies showed that approximately every third hospitalised patient on a given day received antibiotics. While almost $10 \%$ were given antibiotics to treat a health-care associated infection, 6-7 \% were given surgical or medical prophylaxis and the remaining 17-19\% treatment for a community acquired infection. The method and protocols used formed the basis for a pan-European study coordinated by ESAC [18].

Increasing antibiotic use in the elderly population prompted a separate study in 2004 on indications for antibiotic prescribing in 58 nursing homes [19].

It is important that as a result of the efforts to improve antibiotic use, the reduction in prescriptions does not cause unwanted negative effects. A survey of hospital admissions recorded in the national registry of diagnosis in hospital care, showed no increase in the number of patients with acute sinusitis, quinsy and acute mastoiditis despite the reduction in antibiotic prescriptions for children between 1987 and 2003 [20]. Continuous systems for such monitoring need to be implemented. Another important task for Strama is to encourage studies aimed at preserving the efficacy of existing drugs e.g. through modified dosing regimens or drug combinations.

\section{Antibiotic resistance}

A comparatively widespread practice of culturing clinical specimens in combination with well-functioning diagnostic laboratories using harmonised methods (www.srga.org) have formed the basis for the surveillance of antibiotic resistance in Sweden. Surveillance mainly relies on two major sources: notification of any resistance according to the Swedish Communicable Diseases Act and since 2002 a combined surveillance and quality control

\section{F I G U R E 2}

Notifications of infections or colonisation with antibiotic-resistant pathogens notifiable by the Swedish Communicable Disease Act, 1998-2007

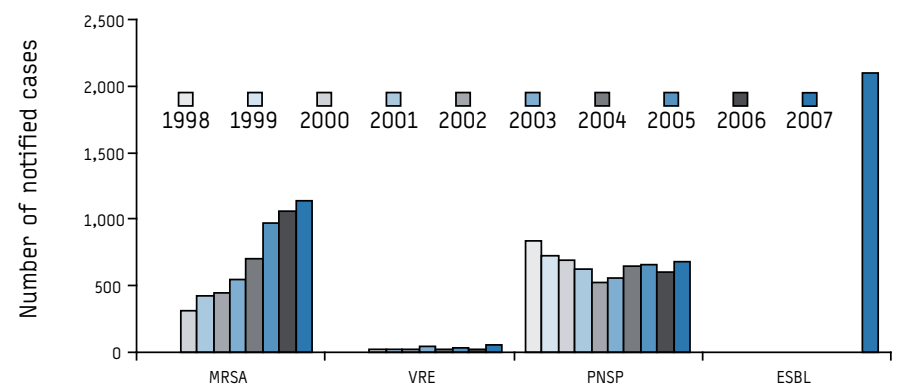

MRSA: methicillin-resistant S. aureus since year 2000

VRE: vancomycin-resistant $E$. feacalis and $E$. feacium since year 2000

PNSP: penicillin-nonsusceptible Streptococcus pneumoniae (minimum inhibitory PNSP: penicillin-nonsusceptible Streptococcus pneumoniae

ESBL: extended spectrum beta-lactamase-producing Enterobacteriaceae, since ESBL: programme (RSQC surveys) that was further developed into the web-based ResNet (http://130.237.97.245/ResNet/index.jsp). National antibiotic susceptibility data are presented regularly on the internet. Figure 2 illustrates reporting according to the Swedish Communicable Diseases Act. While the proportion of S. pneumoniae with decreased sensitivity to penicillin $V$ has stabilised, the number of notified cases of methicillin-resistant Staphylococcus aureus (MRSA) has increased, ESBL-producing Enterobacteracaeae have turned into an endemic situation and, most recently, the hitherto largest outbreaks of vancomycin-resistant enterococci (VRE) is ongoing in the Stockholm region. Still, Sweden is among the countries with the lowest rates of MRSA (still below $1 \%$ ), $S$. pneumoniae can still be treated with penicillin $\mathrm{V}$ and the rate of Escherichia coli-producing ESBLs is below $5 \%$.

\section{Conclusions}

Strama's multidisciplinary and multisectorial programme has developed into a coordinated national effort that has contributed to a decrease in antibiotic use without measurable negative consequences. Furthermore, resistance levels are still comparatively low in Sweden. Some factors that have paved the way for this success have been the utilisation and early involvement of preexisting structures and resources such as the communicable disease officers, the multi-disciplinary approach, the collaboration with the local drug and therapeutics committees and microbiology laboratories and the political support at national level. The most suitable structure for such local nodes will no doubt differ from one country to the next and may take some extra resources to identify and put in place. Particular difficulties can be expected when trying to collect local data sent to different (remote) microbiology laboratories and to develop mechanisms to aggregate prescriptions from individual prescribers or health-care facilities. Not least, regular collaboration with national and regional news media has been one of the key strategies.

Recently, however, antibiotic sales seem to have started to rise again and resistance is increasing in several species. This must be met by intensified information and education campaigns, aimed at doctors as well as the general public, on the rational use of antibiotics and the promotion of compliance with basic hygiene in the health-care sector. Examples of areas which call for further attention are antibiotic use in long-term care facilities, among private health-care providers, to treat sexually transmitted diseases (STIs) and for some chronic conditions such as acne, chronic obstructive pulmonary disease and diabetic foot infections. To achieve this goal, all local groups should be formally supported with a defined mission incorporated in the patient safety and quality work by 2010 .

\section{References}

1. The National Board of Health and Welfare. Swedish plan of action against antibiotic resistance. Stockholm, 2000. Available from: http://soapimg.icecube. snowfall.se/strama/SPAR,_engelsk_version.pdf

2. Swedish Ministry of Health and Social Affairs. Strategy to prevent antibiotic resistance and health-care associated infections. Fact sheet 2008 No.8, May 2006. Stockholm. Available from: http://soapimg.icecube.snowfall.se/strama/ Prop\%20Engelsk.pdf

3. Mölstad S, Erntell M , Hanberger H, Melander E, Norman C , Skoog G, et al. Sustained reduction of antibiotic use and low bacterial resistance. A 10- year follow-up of the Swedish STRAMA programme. Lancet Infect Dis 8(2):125-32. 
4. Struwe J. Fighting antibiotic resistance in Sweden- past, present and future Wien Klin Wochenschr 2008; 120(9-10): 268-79.

5. J Struwe, B Olsson-Liljequist (editors). SWEDRES|2007 - A Report on Swedish Antimicrobial Utilisation and Resistance in Human Medicine. Strama, The Swedish Strategic Programme against Antibiotic Resistance, and the Swedish Institute for Infectious Disease Control. Stockholm, 2007. Available from: http://www.smittskyddsinstitutet.se/upload/Publikationer/swedres-stramasmi-2007.pdf

6. Hanberger H, Burman LG, Cars O, Erlandsson M, Gill H, Nilsson LE, et al. Low antibiotic resistance rates in Staphylococcus aureus, Escherichia coli and Klebsiella spp but not in Enterobacter spp and Pseudomonas aeruginosa: a prospective observational study in 14 Swedish ICUs over a 5-year period. Acta Anaesthiol Scand 2007;51(7):937-41.

7. Hanberger H, Erlandsson M, Burman LG, Cars O, Gill H, Lindgren S, et al. and the ICU-STRAMA Study Group. High antibiotic susceptibility among bacterial pathogens in Swedish ICUs. Report from a nation-wide surveillance program using TA90 as a novel index of susceptibility. Scand J Infect Dis 2004; 36(1):24-30.

8. Hanberger H, Arman D, Gill H, Jindrák V, Kalenic S, Kurcz A, et al. Surveillance of microbial resistance in European Intensive Care Units: a first report from the Care-ICU programme for improved infection control. Intensive Care Med. 2008 Aug 1. [Epub ahead of print].

9. Strama: ESBL in enteric bacteria. Proposed action plan. November 2007 Stockholm: Strama: Swedish Strategic Programme against Antibiotic Resistance. Available from: http://soapimg.icecube.snowfall.se/strama/Strama\%20ESBL\%20 eng.pdf

10. Lundborg CS, Olsson E, Mölstad S: Swedish Study Group on Antibiotic Use. Antibiotic prescribing in outpatients-a-1- week diagnosis-prescribing study in 5 counties. Scand J Inf Dis 2002;34(6):442-8.

11. André M, Odenholt I, Schwahn A, Axelsson I, Eriksson M, Hoffman M, et al. Swedish Study Group on Aantibiotics Use. Upper respiratory tract infections in general practice: diagnosis, antibiotic prescribing, duration of symptoms and use of diagnostic tests. Scand J Inf Dis 2002; 34(12):880-6.

12. Andre M, Eriksson M, Mölstad S, Stalsby-Lundborg C, Jakobsson A, Odenholt I; Swedish Study Group on Antibiotic Use. The management of infections in children in general practice in Sweden: a repeated 1-week diagnosisprescribing study in 5 counties in 2000 and 2002. Scand J Infect Dis. 2005;37(11-12):863-9.

13. André M, Mölstad S, Stålsby Lundborg C, Odenholt I,. Management of urinary tract infections in primary care: a repeated 1-week diagnosis-prescribing study in 5 counties in Sweden in 2000 and 2002 . Scand J Infect Dis. 2004;36(2):134-8.

14. André M, Eriksson M, Odenholt I. [Treatment of patients with skin and soft tissue infections. Results from the STRAMA survey of diagnoses and prescriptions among general practitioners] Lakartidningen. 2006;103(42):3165-7. Swedish.

15. Andre M, Vernby $\AA$, Odenholt I, Lundborg CS, Axelsson I, 5 Eriksson M, et al. Diagnosis-prescribing surveys in 200, 2002 and 2005 in Swedish general practice: consultations, diagnostics and treatment choices. Scand J Infect Dis 2008;40(8):648-654

16. Cars 0, Sandberg T. Restrict the use of fluoroquinolones in UTI [in Swedish]. Information Uppsala: Läkemedelsverket; 1996; 7: 3-4

17. Erntell M, Skoog G, Cars O, Elowson S, Hanberger H, Jorup C et al. The STRAMA-programme (The Swedish Strategic Programme for the Rational use of Antimicrobial agents), Stockholm, Abstract 0 404, 18th ECCMID 2008.

18. Erntell M, Ansari F, Goossens H, Davey P. ESAC II Hospital Care Subproject 2005-2007: Patterns of Antibiotic Use in Relation to Diagnose in 19 European Hospitals in 2006, Point Prevalence Study (PPS). 17th European Congress of Clinical Microbiology and Infectious Diseases 2007, 0166.

19. Pettersson E, Vernby $\AA$, Mölstad S, Lundborg CS. Infections and antibiotic prescribing in Swedish nursing homes: a cross-sectional study. Scand J Infect Dis 2008;40(5):393-398.

20. Cars 0 and Olsson Liljequist B, editors. SWEDRES 2005. A report on Swedish antibiotic utilisation and resistance in human medicine. Stockholm: The Swedish Strategic Programme for the Rational Use of Antimicrobial Agents (STRAMA), and the Swedish Institute for Infectious Disease Control. Available from: http://soapimg.icecube.snowfall.se/strama/Swedres\%202005.pdf

This article was published on 13 November 2008.

Citation style for this article: Mölstad S, Cars 0, Struwe J. Strama - a Swedish working model for containment of antibiotic resistance . Euro Surveill. 2008;13(46):pij=19041. Available online: http://www.eurosurveillance.org/ViewArticle.aspx?ArticleId=19041 